Journal of Teacher Education for Sustainability, vol. 22, no. 1, pp. 111-123, 2020

\title{
Exploring EFL Teachers' Moral Identity: The Case of Iranian Teachers
}

\author{
Davoud Amini, Sima Najafi, and Bahram Behin \\ Azarbaijan Shahid Madani University, Tabriz, Iran
}

\begin{abstract}
Educating teachers for sustainability requires that teachers be considered as the mediators of change. To achieve this goal, a constructive teacher-learner relationship is essential where values and ethicality play a crucial role. Investigating language teachers' moral identity as an important aspect of teacher cognition can yield useful insights into the kind of relationship which is congenial to the desired whole-person development. The present qualitative study intended to explore the nature of moral dilemmas in language classes and teachers' criterial beliefs in responding to these dilemmatic situations. A systematic coding analysis of the recorded interviews with eight Iranian experienced EFL teachers revealed that they encountered moral dilemmas in both disciplinary and educational aspects of the teaching process. They referred to their knowledge, experience, intuitive sense as well as the teaching context and learners' history as sources of their moral judgment. The findings on teachers' moral identity uphold implications for teacher education.
\end{abstract} Key words: teacher cognition, moral dilemmas, moral identity, sustainability, EFL

\section{Introduction}

An appropriate level of social development is one of the three tenets of sustainability, the other two being economic growth and environmental protection. Long-term sustainable development is not attainable before individuals and societies change their thoughts and behavior. In this regard, education plays a key role in achieving sustainability. According to Hofman-Bergholm (2018), sustainable education is intrinsically "valuedependent" (p. 25). Both teachers and learners need to become aware of the way their actions might affect the whole process of social development. If sustainable development is interpreted as encouraging sustainable change in learners, the act of teacher education should inevitably go beyond providing the knowledge and art of teaching to pre-service teachers because in this view, teachers are considered as mediators of change rather than disseminators of knowledge (Williams \& Burden, 1998). That is how the ethics of teaching gain priority against the knowledge or art of teaching. Therefore, a reflective analysis of teachers' ethical beliefs is a conductive method for studying teacher-learner relationship in that it offers teachers the opportunity to deconstruct their holistic behavior and raise awareness about moral convictions in their practice (Kostoulas-Makrakis, 2010). 
As an important concern in second language teacher education, the research on teacher cognition involves "understanding what teachers think, know, and believe" (Borg, 2009, p. 1). Teachers are active and thinking decision makers, whose way of acting in the classroom comes directly from, and is determined by their unobservable mental states. According to Borg (2003), teachers as decision makers "make instructional choices by drawing on complex, practically-oriented, personalized and context-sensitive networks of knowledge, thoughts and beliefs" (Borg, 2003, p. 81). One of the issues related to teachers' mental cognition is their moral mentality. Ethical issues normally reside within the heart of language teaching. Occasionally, dealing with moral complexities in language classes turns to a problem for teachers. To wisely handle the moral dimension of language teaching, teachers often go through some conflicts. Moral complexities of language teaching are in the guise of what has come to be known as "moral dilemmas" reported by teachers in language teaching profession (Komorowska, 2016). Regarding teacher-student relations, in which moral conflicts are more conspicuous for teachers, they deal with multifaceted actions and behaviors, which in turn determine what orientations the teaching-learning process will opt for.

Although the moral nature of teaching is accepted as universal, the way teachers handle moral issues is, for some part, personal, and teachers respond to moral dilemmas differently. In fact different moral identities pose a variety of moral stances toward moral dilemmas. The quality of teacher-student relations, and as a consequence, the quality of teaching and learning, is highly influenced by the stances teachers take. The moral dimension of language teaching has been a neglected area for EFL teachers. First of all we need to understand what teachers are experiencing in their classrooms as they make their moral decisions using their moral intelligence. The overall theme of the current study revolves around teaching ethics and the morally dilemmatic nature of language teaching, followed by an examination of what type of moral identities language teachers adhere to an aspect of their moral cognition.

\section{Literature Review}

A survey of the applied linguistics literature on English teaching and teacher education signifies a mass of studies addressing teacher identity as a multifaceted area of inquiry. Teachers' cognitive and affective insights concerning classroom procedure are immensely affected by their identity (De Costa \& Norton, 2017; Thi \& Anh, 2018). According to Higgins and Ponte's (2017) definition "teacher identity refers to who teachers are and what source of experiences they bring to the classroom setting" (p. 16). Teachers' cognition is co-determined by their personality and other factors present in the context of teaching. Miller, Morgan, and Medina (2017) treat teacher identity as the ethical self-formation which is essential to professional development.

Identity and morality are both inherent aspects of teacher cognition and indivisible from each other (Miller, Morgan, \& Medina, 2017). Although there is not a single interpretation of moral identity, Moshman (2008) believes that "to have a moral identity is to have an explicit theory of yourself as moral agent - an agent who is committed to acting on the basis of respect and/or welfare of others" (p. 89). This explication echoes the core definition of morality in that it observes the concern for others as the crux of moral behavior. Thus, teachers' moral identity reflects their value orientations and preordains their behavioral options in the teaching process. 
In spite of its centrality, teachers' moral mind has not been devoted the attention it deserves. Among the few studies conducted in Iranian context, Akbari and Tajik (2012) tried to find out what moral patterns exist in the practitioners' mind by considering both their pedagogical and moral thoughts through stimulated recall procedure. The results demonstrated the presence of more pedagogical thought units than moral ones implicating that EFL teachers are preoccupied with the professional aspects of their practice rather than the moral aspects of student-teacher relations. Meanwhile, Johnston (2008) believes that language teaching is value-laden because teachers' relation with students equals their interaction with fellow humans, and humane interactions are basically moral. Moreover, the ultimate goal in sustainable education is to change people, and the assumption is that this change will be for the better, which is a moral matter. So, the teachers' decisions are mainly based on moral principles rather than pedagogical instructions; they have to be on the basis of teachers' beliefs systems about what is right or wrong for the students as well as themselves.

Moral meanings of the teaching-learning process are highly dependent on the contextual details of teacher-student relations. In other words, the same action or behavior by different teachers with different students can be interpreted with a variety of moral meanings. In their relations with the students, teachers face different moral dilemmas. A moral dilemma refers to a difficult situation in which a teacher can choose among competing courses of action (Kan, Ponte, \& Verloop, 2010). Different researchers have adopted various lines of inquiry for studying moral dilemmas in teaching. The description of moral dilemmas is context-specific for teachers and researchers, but the nature of the dilemmas and the conflicts they bring about for teachers are universally accepted. Researchers have tried to investigate the issue from different points of view. Kan et al. (2010), for instance, adopted the term "bumpy moment" to signify dilemma-laden moments. By the term bumpy moment they meant a situation in which there are competing courses of action that a teacher can take.

In their Ethical-Values pedagogical model Holland, Mulcahy, Besong, and Judge (2012) introduced a forth element to be accommodated into common models of pedagogy; they considered an ethical values basis as essential to sustaining cognitive, social and teaching elements by asserting that: "for the educators, reflective and reflexive practice is critical to understanding own ethical-values base and how this shapes the learning content, processes, interactions and, ultimately, the learning of learners" (Holland et al., p. 46).

The main source of dilemma lies in various contradictory orientations toward the teaching profession by learners, parents, school administrators and teachers. For instance, teachers report that they find conflicts between institutional demands and the needs of students (Pope, Green, Johnson, \& Mitchell, 2009). Pope et al. (2009) believe that to deal with these kinds of conflicts, we need explicit guidelines specifically for avoiding unethical behavior and this would improve teachers' practices. The researchers proposed a list of conflicts as an organizing framework. Among the conflicting elements mentioned by the participants was the conflict between student need and institutional requirements. Following a similar line of enquiry, Donahue (1999) highlighted an ethical dilemma faced by teachers' in service-learning. According to the findings, there were gaps between service-learning and the actual practice of teaching regarding ethics. The question lay in the dilemmatic choice between following pure institutional rules and deciding personally as a teacher. This pertains to the tensions between teachers' democratic teaching style 
and their moral or educational views, which means it is not easy to apply a democratic teaching style in a critical pedagogy, an issue put forward by McKinney (2005).

Generally speaking, the research on the basis of teachers' moral response and moral reasoning in the language classroom is still in its infancy as the study of moral conflicts in teaching has been a neglected area in language education so far. One such area concerning the dilemmatic nature of language teaching, throughout the related literature, concerns the ethics of teacher-student relations. Such studies must directly address the morality at play in different facets of teacher-student relations. Accordingly, the following research questions were posited to carry out a preliminary exploration on the issue:

1. What aspects of language classes regarding teacher-student relations pose moral dilemmas to Iranian EFL teachers?

2. What are Iranian EFL teachers' considerations in responding to moral dilemmas?

3. What are the criteria, in Iranian EFL teachers' belief, for establishing moral relationship with the students?

4. How do Iranian EFL teachers justify their reasoning for their moral decisions?

\section{Method}

\section{Design}

As an exploratory research, this study resorted to a qualitative interview-based design for both collecting and analyzing data. Studying aspects of teachers' cognition is an indisputably complicated procedure. Ascertaining the validity of such researches demands a multi-level analysis. As asserted by Pipere, Veisson, and Salite (2015), "in education for sustainability development (ESD), qualitative studies should be aimed at understanding the motives and discourse of SD" (p. 12). Therefore, the data required for the current research was collected by means of conducting interviews in order to acquire and categorize moral dilemmas faced by EFL teachers and teachers' moral reasoning sources regarding teacher-student relations as well as the moral identity of the teachers. The whole interview sessions were held in English.

\section{Participants}

The participants of this study were 8 experienced Iranian EFL teachers ( 4 male and 4 female) who taught classes simultaneously at both university and language institutes at different instructional levels in Tabriz, Iran. All the participants held M.A. or Ph.D. degrees in English language. As experienced teachers, the participants had 8-20 years of teaching background. Teachers with a high level of education and teaching experience were selected based on purposive sampling because it is reported in the literature that more experienced teachers face and deal with more dilemmatic situations.

\section{Procedure and Data Analysis}

For answering the four questions of the research, a semi-structured interview was designed and conducted for each participant to openly discuss the questions from the teachers' perspectives. It was clearly explained to the participants that all the recorded files would be destroyed after transcription and also all the data would be kept confidential 
and reported in the study anonymously. The interview sessions lasted between 10 to 50 minutes depending on the natural willingness and engagement level of the teachers. The interviews were recorded and transcribed later on. After several times of reading through the transcriptions and highlighting the relevant issues, the transcriptions were broken into chunks. After that, items related to each theme derived from the research questions were extracted and grouped together. A systematic coding procedure was applied in order to categorize the elicited items according to their relevance and significance. In addition, through memoing, some underlying meanings were deciphered to be associated with systematically coded categorizations. These underlying meanings explained categories in detail and added significance to the data. In case of ambiguity, the interviewed teachers were reached back and were consulted on the point at issue.

\section{Results and Discussion}

\section{Moral Dilemmas}

The first research question dealt with an enquiry on the nature of moral dilemmas EFL teachers encountered. The analysis indicated that the dilemmatic nature of language teaching classes encompass a disciplinary dimension and an educational facet (Figure 1). The most frequently mentioned dilemma by EFL teachers in interviews regarding the disciplinary concerns was the difficult times in language classrooms brought about by disobedient students. The EFL teachers characterized this group of learners with such descriptions as noisy, naughty, difficult, tough and impolite. These students might turn language class into a problematic situation because of interrupting natural process of teaching and classroom interactions.

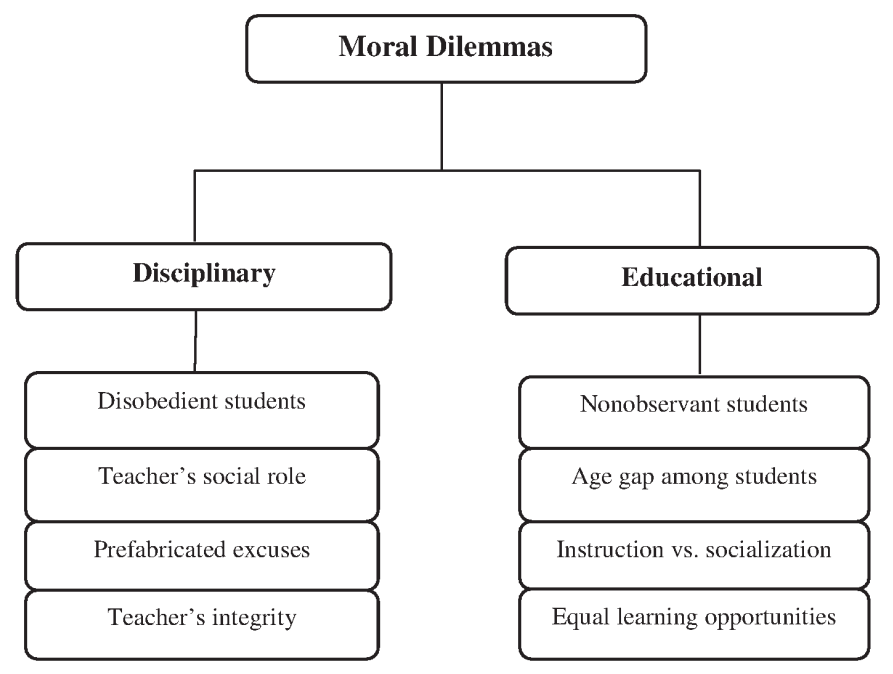

Figure 1. Moral dilemmas reported by teachers

Another problem reported by the participants was the teachers' struggle to choose between having a mediator's role and a personal role. In the process of language teaching, there are occasions when students expect the teachers to socialize in more intimate manner. In such cases, it is difficult for the teacher to decide whether to maintain a role 
as a mediator only who facilitates students' learning, or to express their personal beliefs, attitudes and feelings as a free communicator. While taking only the role of a mediator may lead to a boring and less joyful atmosphere, too much revelation of personal identity within the context of classroom may turn the setting into a personal-idea-sharing platform.

Another important dilemmatic burden was the difficulty of differentiating learners' veracious excuses from spurious ones. Students may address the teacher with a variety of excuses made for different purposes. Recognizing whether these excuses are real or they are just pre-designed scenarios to dupe the teacher becomes a moral dilemma for teachers. Being too rigorous may discourage the learners and break the constant rapport. But considering the other side of the coin, being too sympathetic always runs the risk of easily being fooled into false persuasions.

The participants mentioned still another disciplinary dilemma they faced, i.e., possible effects of students' favor-seeking behavior on the teachers' judgment. Maintaining integrity and commitment to behaving professionally in evaluating and judging students, and not being wheedled by students' flattery or sweet talk can pose a moral challenge to teachers.

Moral dilemmas do not simply belong to disciplinary aspects of language teaching. The participants proffered educational dilemmas too. According to the interviewees, one of the biggest challenges faced by EFL teachers is brought about by those students who do not comply with the educational requirements, e.g., in doing the assignments. This noncompliance may spring from different causal sources such as lack of internal or external motivation, absence of commitment or sense of belonging, inappropriate orientations and inclinations, reclusiveness and unwillingness to communicate.

Another important educational dilemma pertained to the age differences among students. One problem is that, due to learners' varying level of cognitive and social development, certain learning material and activities which are pedagogically serviceable for one age group may be inappropriate for another group sitting in the same class. Another dilemma is that some learners might be too young to enter into certain cognitive activities. This connects us to another important educational dilemma. When teachers engage the learners in a discussion, for instance, some students might not possess the psychological or social integrity to get engaged, especially in the case of controversial topics. Moreover, teachers need to decide whether to set a mere educational milieu for language learning or arrange a setting in which social transactions take place. Due to the communicative nature of language classes and an inevitably versified tasks and activities performed in language classes, maintaining fair relations with all students in terms of participation schemes was another big challenge of teachers. Surely, the moral dilemmas of language teaching go far beyond what has been presented in this section which are only a few examples of the immense field of the dilemmatic nature of teaching.

\section{Teachers' Ethical Considerations}

The second research question concerned the nature of the teachers' considerations in responding to moral dilemmas. A summary of the analysis of the encoded data from interviews is displayed in Figure 2. By and large, the interviewees signified two general observations, i.e., the interpersonal relations and academic requirements as being decisive in reacting to ethical dilemmas. 


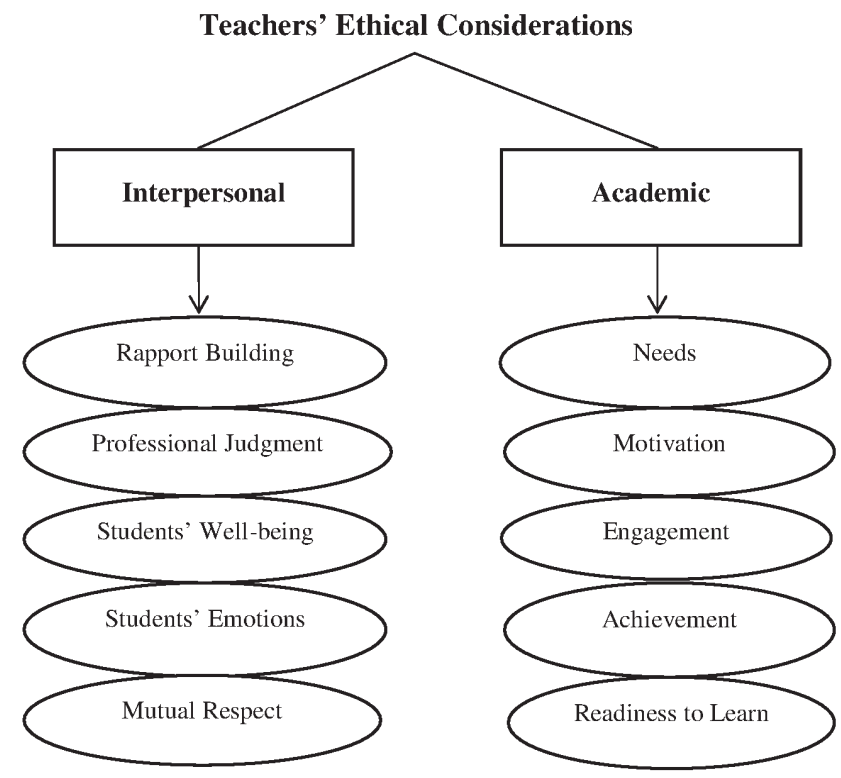

Figure 2. Teachers' ethical considerations in responding to moral dilemmas

Teaching is as much a moral responsibility as it is a cognitive process. EFL teachers in this study asserted that they made allowance for some ethical touchstones. The nature of language teaching and learning willy-nilly engages teachers and learners in interpersonal interactions carrying with them a bunch of ethical concerns. For instance, beginning every session of their classes with establishing an appropriate kind of rapport, which sort of breaks the ice, is part of language teaching job. In the absence of an appropriate rapport, it seems impossible to establish effective interactions with learners, which is an inherent property of any successful language teaching profession.

Another ethical consideration mentioned by the participants was the students' on the spot feelings concerning both their social presence and academic achievements. In addition to social emotions which are similar to those experienced in non-instructional settings, there are a set of emotions which are specifically associated with academic achievement goals. According to Weiner (2007), learners experience a set of moral emotions in the classroom, including admiration, anger, gratitude, guilt, indignation, jealousy, regret, and schaden freude. A proper treatment of learners' moral emotions requires moral judgments on the part of the teacher.

An ethical teacher also takes care of students' well-being in the classroom. Whether all the learners are comfortable and well-off in the classroom is an important consideration. In fact, learners attend their classes with two divergent priorities in mind: The first one is to ensure that they are improving their competence by learning new things. The second is to protect their self-image and well-being (Boekaerts, 2007). The latter is closely associated with the state of learners' moral affect. Some of the participants also put forth the complexity of impartial judgments on students. Furthermore, teachers made a point of politeness in moments of interactions with students as another key consideration. They also highlighted mutual respect and friendship in teacher-student relations. 
These interpersonal considerations seem to be essential in providing the primary conditions for the learning to take place. How students feel will determine part of how they are involved in the process of learning. For instance, unmotivated learners do not have the same degree of engagement as motivated learners'. This warns teachers to take care of their students' feelings in the classroom. Meanwhile, ethical teachers have academic considerations too. In this regard, the participants gave prominence to students' needs, motivation, engagement, achievement and their readiness to learn as some of the important factors they took account of when in urgency of a moral judgment.

\section{Morality Standards in Teacher-Student Relations}

EFL teachers involved in this study stated that some factors play key roles in their relationship with students. Some believed that these kinds of relations are culture-bound. That is, the specific culture of the place one belongs to or teaches in will, for some part, define how the teacher ethically approaches the classroom interactions. Also, students' cultural background and their perceptions on language classes and learning will evidently affect the quality of teacher-student relations. Some of the participants also talked about the role of students' gender in their relationship. They emphasized that when dealing with opposite gender, they were more mindful of both cultural and personal creed. Students' and teachers' age was another key factor involved in teacher-student relations. Every age group of students requires its own language, behavior, and treatment on the part of the teacher. The smaller the age gap between the teacher and the learners, the more affinity would exist between them. Teachers and learners with narrower age differences have much more in common; this brings some sort of mutual understanding in teacher-student relationship (Figure 3).

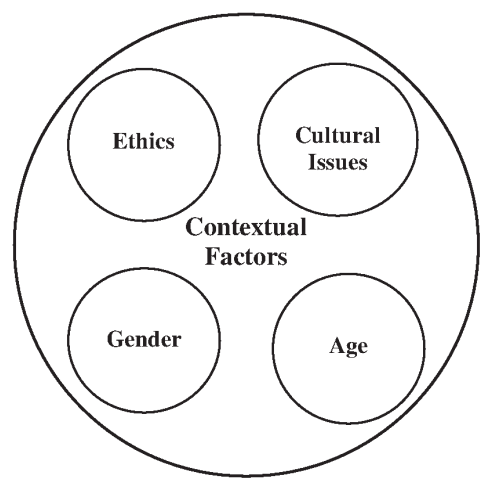

Figure 3. Morality standards involved in teacher-student relations in EFL classes

Almost all the participants believed that building an appropriate kind of relationship with the students based on the above-mentioned moral standards will foster language teaching. Teacher-student relation is a matter of bipolar extremes. On the one end is "distance" and on the other is "affinity" or "intimacy". EFL teachers in this study considered both extremes as perilous and believed in moderation on this relational axis. Teachers should not build blocks between themselves and their students. They need to respect students' feelings and make them feel good in the classroom (Amini, 2014). This creates some sort of positive atmosphere for them to participate actively in the teaching/learning process. 
From ethical point of view, teachers get as close to their students as their privacy is not jeopardized, social regulations of the institute are not violated, and the students' feelings are not hurt. Taking these relationships inconsiderately, will bring about misunderstandings. As a tangible case in point, too much proximity will immediately be interpreted by the students as laxity on the part of the teacher and as a consequence the teacher will run into serious problems of discipline and as a result, in turn, moral challenges related to discipline will be intensified. All in all, the intimacy must ultimately be at the service of teaching; all these relationships and considerations are established with the aim of facilitating learning and teaching. Accordingly, almost all EFL teachers in this study believed in the balance in teacher-student relationship. But reaching an ideal balance in relationships is believed to require high levels of moral intelligence.

\section{Teachers’ Moral Reasoning Basis}

The moral decisions teachers make spring from several sources. A summary of surmised sources of reasoning, as reported by participants of this study, are displayed in Figure 4. One of the most important causes of taking a moral action is teachers' knowledge. Teachers' knowledge includes the academic information they possess in their own subject area, their readings and the training courses they have received, their perceptions on language teaching as well as language learners, their value system, their professional personality and teaching objectives. For a great part, teachers' own personal values will shape their moral decision making. Thus, teachers' knowledge is a wellstocked source that language teachers can refer to, in their moral decision-making process.

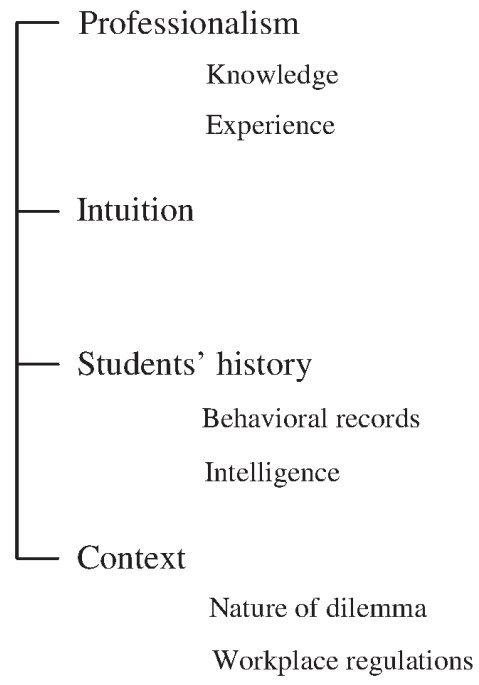

Figure 4. Teachers' moral reasoning basis

Another important criterion for taking moral actions is teachers' experience. Teachers accumulate valuable experiences during their teaching years, teaching in different situations to diverse learners, and working with companions in different circumstances. This valuable reserve of experience helps teachers to choose the best option among many competing courses of action available to them when running across moral challenges. 
For some teachers, the intuitive sense is the only available source for teachers to base their moral decisions on; Teacher's resorting to intuition in telling apart right from wrong in dilemmatic situations is in line with Haidt's Social Intuitionist Model of moral judgment (Haidt, 2001).

Students' backdrop was reported by EFL teachers in this study as another source of moral actions. Student's history of behavioral records in the classroom, their keenness in meeting the expectations set for them, their perceptions of language learning classes, their readiness to progress in competence, and the overall profile of students will shape teachers reactions. For instance, in facing excuses raised by students, EFL teachers in this study admitted that they typically tend to succumb to the participating and intelligent students rather than inactive ones.

However, the decisions teachers make, are totally context-sensitive. That is why no behavior or action can be studied out of its specific contextual situation. Teachers make decisions based on the kind of dilemmas they face. A particular moral behavior which is appropriate in a certain dilemmatic situation might be totally inappropriate in another context simply because dilemmas are interpreted differently if the context is altered. Thus, both moral dilemmas and teachers' response to them are totally contextdependent.

Another determinant factor which shapes teachers' moral behavior is the workplace itself. In some institutes, the emphasis is only on the students' attendance and achievements with little attention devoted to ethical concerns while in others, ethical considerations are brought into the circle. This important issue might overshadow how teachers handle moral challenges in their classrooms.

To sum up the findings, due to the ethical nature of language teaching, teachers deal with moral dilemmas in their teaching. Moral dilemmas rise from a variety of sources, and they are individual in nature. Teachers interpret and analyze moral dilemmas they face based on their personal worldviews and ideology on the ethical nature of language teaching. This is also the source of how they respond to moral dilemmas. How they see dilemmatic situations they encounter and how they dispose themselves towards the teaching ethics determine how they react in response to the dilemmatic situations they are put in; and their behavior, in turn, shapes their moral identity. This is part of how they organize and present lessons by means of manipulating the moral side of classroom atmosphere. This study found that teachers care for several interpersonal and academic issues to accomplish such manipulations, justifying their intended milieu for teaching. For establishing a moral relationship with their learners, teachers consider several conditions to be present in their relations. The quality of their relation relies on the way their moral worldviews fit into their teaching practices.

\section{Conclusion}

Language teacher education cannot be solely conceptualized and rendered in terms of pedagogical procedures. Language teaching needs to be viewed as comprising several tasks calling for teachers' pedagogical knowledge, experience, and epistemological awareness. All the requirements for effective teaching meet together in a specific context of an effortful ethical action. The complexity of this context poses dilemmatic challenges to teachers in every minute of classroom teaching and interaction. In fact, how teachers view the ethical side of teaching is part of their moral identity which is the determinant 
root of teachers' moral decisions and actions in the classroom. The diversity of teachers' decisions and responses, then, comes from the diversity of mental ethical conceptualizations set through cognition development as part of identity formation and shaped through gaining experience.

The dilemmatic nature of teaching is accepted as a universal entity. Because of this universality, there is a need for specified and clearly-set guidelines for EFL teachers' moral judgment and moral reasoning base, for taking right moral actions and for justifying all their moral decisions and beliefs.

Moral requirements of a congenial teacher education highlight two sustainability issues. First, because of the fact that sustainability in teacher education is a value-laden concept (Hofman-Bergholm, 2018), students must develop critical thinking skills to extract their own values regarding how their and their teachers' actions contribute to sustainability. In this regard, a proper kind of teacher-student relationship that nurtures critical thinking will rely, to a great extent, on the recognition and incorporation of student-teacher relations. Secondly, Teachers should be trained for systems thinking (Hofman-Bergholm, 2018); that is, they must become aware of how their moral decisions and actions as a member of the educational system leaves a benign or malign effect on students' ever-changing movement towards sustainable development.

For providing an ideal atmosphere for learning, a fine-settled teaching atmosphere seems to be fundamental. One crucial step is to develop more room for ethical discussions in education. Teachers and learners must be made aware of their ethical knowledge base and how it fits into teaching and learning goals. Providing thoughtful ethical insights for teachers, learners, institutions, and even parents will pave the way for fine-tuning the teaching-learning process in order to provide learning development spaces.

Moral dilemmas of language teaching do not only belong to teacher-student relations; dilemmatic challenges exist in all areas of English language teaching. It means that, in addition to teacher-student relations, dilemmas related to institutions, language teaching methodology, curriculum, and even parents' involvement need to be focused on separately to uncover more and more realities about the ethical nature of language teaching. Also, the reason(s) behind all these dilemmatic challenges and the sources they spring from, could be further investigated for finding out required steps to take to resolve them.

Teachers' reactions to moral dilemmas and how they interpret them is a matter of what kind of "teaching persona" they have developed. Studying teachers" moral persona might be one effective strategy for examining different facets of their moral reflective and reflexive behavior in their classes.

\section{References}

Akbari, R., \& Tajik, L. (2012). Second language teachers' moral knowledge base: A comparison between experienced and less experienced male and female practitioners. Journal of Moral Education, 41(1), 39-59.

Amini, D. (2014). Teacher and learner in humanistic language teaching. Journal of Applied Linguistics and Applied Literature: Dynamics and Advances, 2(2), 13-24.

Boekaerts, M. (2007). Understanding students' affective processes in the classroom. In Pekrun, R., \& Schutz, P. A., Emotion in education (pp. 37-56). New York: Elsevier Inc. 
Borg, S. (2003). Teacher cognition in language teaching: A review of research on what language teachers think, know, believe, and do. Language Teaching, 36(2), 81109.

Borg, S. (2009). Introducing language teacher cognition. Retrieved from http:// www.education.leeds.ac.uk/research/files/145.pdf

De Costa, P. I., \& Norton, B. (2017). Introduction: Identity, transdisciplinarity, and the good language teacher. The Modern Language Journal, 101, 3-14.

Donahue, D. M. (1999). Service learning for pre-service teachers: Ethical dilemmas in classroom assessment. Teaching and Teacher Education, 15, 685-695.

Haidt, J. (2001). The emotional dog and its rational tail: A social intuitionist approach to moral judgment. Psychological Review, 108(4), 814-834.

Higgins, C., \& Ponte, E. (2017). Legitimating multilingual teacher identities in the mainstream classroom. The Modern Language Journal, 101, 15-28.

Hofman-Bergholm, M. (2018). Changes in thoughts and actions as requirements for a sustainable future: A review of recent research on the Finnish educational system and sustainable development. Journal of Teacher Education for Sustainability, 20(2), 19-30.

Holland, C., Mulcahy, C., Besong, F., \& Judge, M. (2012). Ethical-values pedagogical model. Journal of Teacher Education for Sustainability, 14(2), 41-53.

Johnston, B. (2008). Values in English language teaching. New Jersey: Lawrence Erlbaum Associates.

Kan, C. A. V., Ponte, P., \& Verloop, N. (2010). How to conduct research on the inherent moral significance of teaching: A phenomenological elaboration of the standard repertory grid application. Teaching and Teacher Education, 26, 1553-1562.

Komorowska, H. (2016). Dilemmas in language teaching and teacher education. doi: 10.14746/gl.2016.43.1.6

Kostoulas-Makrakis, N. (2010). Developing and applying a critical and transformative model to address education for sustainable development in teacher education. Journal of Teacher Education for Sustainability, 12(2), 17-26.

McKinney, C. (2005). A balancing act: Ethical dilemmas of democratic teaching within critical pedagogy. Educational Action Research, 13(3), 375-392.

Miller, E., Morgan, B., \& Medina, A. (2017). Exploring language teacher identity work as ethical self formation. The Modern Language Journal, 101, 91-10.

Moshman, D. (2008). False moral identity: Self-serving denial in the maintenance of moral self-conceptions. In Lapsley, D. K., \& Narvaez, D. (Eds.), Moral development, self, and identity (pp. 83-109). New Jersey: Lawrence Erlbaum Associates.

Pipere, A., Veisson, M., \& Salite, I. (2015). Developing research in teacher education for sustainability: UN DESD via the Journal of Teacher Education for Sustainability. Journal of Teacher Education for Sustainability, 17(2), 5-43.

Pope, N., Green, S. K., Johnson, R. L., \& Mitchell, M. (2009). Examining teacher ethical dilemmas in classroom assessment. Teaching and Teacher Education, 25, 778-782.

Thi, D., \& Anh, K. (2018). Identity in activity: Examining teacher professional identity formation in the paired-placement of student teachers. Teaching and Teacher Education, 30, 47-59.

Weiner, B. (2007). Examining emotional diversity in the classroom: An attribution theorist considers moral emotions. In Pekrun, R., \& Schutz, P. A., Emotion in education (pp. 75-88). New York: Elsevier Inc. 
Williams, M., \& Burden, R. (1997). Psychology for language teachers: A social constructivist approach. Cambridge: Cambridge University Press.

Correspondence concerning this paper should be addressed to Dr. Davoud Amini, Floor 5, No. 11, Farvardin Street, Razi District, Resalat Avenue, Tabriz, Iran. Zip Code: 5177636880. Email: davoudamini2014@gmail.com 